\title{
SG-II-Up prototype final optics assembly: optical damage and clean-gas control
}

\author{
Dongfeng Zhao ${ }^{1,2}$, Li Wan $^{1}$, Zunqi Lin ${ }^{1}$, Pin Shao ${ }^{1}$, and Jianqiang Zhu ${ }^{1}$ \\ ${ }^{1}$ Shanghai Institute of Optics and Fine Mechanics, Chinese Academy of Sciences, No. 390, Qinghe Road, \\ Jiading District, Shanghai 201800, China \\ ${ }^{2}$ University of Chinese Academy of Sciences, No. 19A Yuquan Road, Beijing 100049, China \\ (Received 8 July 2014; revised 2 December 2014; accepted 29 December 2014)
}

\begin{abstract}
The Shenguang-II Upgrade (SG-II Up) facility is an under-construction high-power laser driver with eight beams, $24 \mathrm{~kJ}$ energy, 3 ns pulse duration and ultraviolet laser output, in the Shanghai Institute of Optics and Fine Mechanics, China. The prototype design and experimental research of the prototype final optics assembly (FOA), which is one of the most important parts of the SG-II Up facility, have been completed on the ninth beam of the SG-II facility. Thirty-three shots were fired using 1- $\omega$ energy from 1000 to $4500 \mathrm{~J}$ and 3- $\omega$ energy from 500 to $2403 \mathrm{~J}$ with a 3 ns square pulse. During the experiments, emphasis was given to the process of optical damage and to the effects of clean-gas control. A numerical model of the FOA generated by the Integrated Computer Engineering and Manufacturing code for Computational Fluid Dynamics (ICEMCFD) demonstrated that a flux within $1-51 \mathrm{~s}^{-1}$ and a $180 \mathrm{~s}$ period is effectual to avoid contaminant sputtering to the optics. The presence of surface 'mooning' damage and surface spots located outside the clear aperture are induced by contaminants such as wire, silica gel and millimeter order fiber and metal.
\end{abstract}

Keywords: Final Optics Assembly; optical damage; SG-II-Up

\section{Introduction}

The Shenguang-II Upgrade (SG-II Up) is a kilojoule-class solid-state laser and targeting facility under construction by the National Laboratory on High Power Lasers and Physics. The amplified $1053 \mathrm{~nm}$ beams from the $\mathrm{Nd}$ :glass driver are transported (at $40 \mathrm{~kJ}$ for $3 \mathrm{~ns}$ ) in $2 \times 2$ quads with eight beams with aperture size $310 \mathrm{~mm} \times 310 \mathrm{~mm}$ to the $2.4 \mathrm{~m}$ diameter target chamber where eight final optics assemblies (FOAs) convert each beam to the third harmonic, separate the residual 1053 and $527 \mathrm{~nm}$ beams, and finally focus the $351 \mathrm{~nm}$ beam onto the target.

The prototype design and manufacture of the FOA have been finished, and it is different from the NIF'FOA and the SG-II'FOA ${ }^{[1-6]}$. The FOA consists of fixed interfaces to the target chamber and five modules that house eight fullaperture optics, as shown in Figure 1. The aperture sizes of these optics are as large as $370 \mathrm{~mm} \times 370 \mathrm{~mm}$. The corresponding functions of the various optics, as shown in the aforementioned figure, are as follows.

Correspondence to: D. Zhao, Shanghai Institute of Optics and Fine Mechanics, Chinese Academy of Sciences, No. 390, Qinghe Road, Jiading District, Shanghai 201800, China. Email: dfzhao@siom.ac.cn
1. Phase plate - conditions the beam phases to form an $\sim 750 \mu \mathrm{m}$ flat-top profile.

2. Vacuum window - provides a near-vacuum FOA environment.

3. Frequency conversion crystals - convert the $1053 \mathrm{~nm}$ beam to a $351 \mathrm{~nm}$ beam.

4. Wedged plate - separates the residual 1053 and $527 \mathrm{~nm}$ light with $351 \mathrm{~nm}$ light, and the refractive lowenergy $351 \mathrm{~nm}$ light to a power sensor on the output surface.

5. Focus lens - focuses the $351 \mathrm{~nm}$ beam onto the target; the focal length is $2234 \mathrm{~mm}$.

6. Beam sampling grating (BSG) and main debris shield (MDS) - providing a low-efficiency grating to the input surface for energy sampling (calorimetry) and large-object protection for upstream (more expensive) optics.

7. Disposable debris shield (DDS) - thin, inexpensive optics for primary debris protection.

The frequency converter is a cascade sum-frequency generation design consisting of a $12.5 \mathrm{~mm}$-thick Type-I KDP 


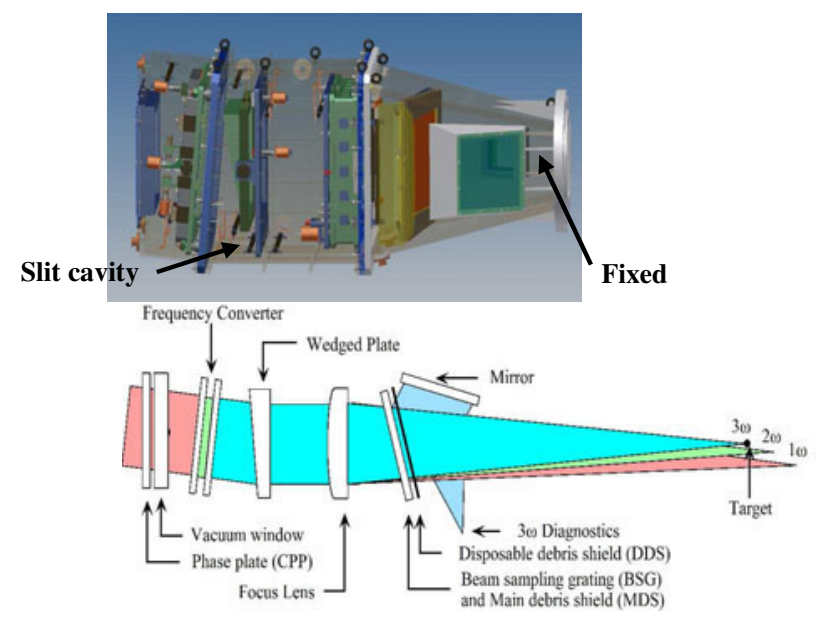

Figure 1. The prototype FOA is composed of fixed interfaces to the target chamber and five modules that house eight full-aperture optics. The clear aperture size is $310 \mathrm{~mm} \times 310 \mathrm{~mm}$.

doubler and a $10.5 \mathrm{~mm}$-thick Type-II KDP tripler, optimized to achieve $>70 \%$ peak power conversion efficiency to the third harmonic at a $1 \omega_{0}$ driver irradiance of $3 \mathrm{GW} \mathrm{cm}^{-2}$ (Ref. [7]). The wedged plate, which is a prism with an edge angle of $11.22^{\circ}$, combines with the focus lens to realize a $2 \mathrm{~mm}$ separating distance of the fundamental and second harmonic away from the third harmonic target. The focus lens has a $45 \mathrm{~mm}$-thick meniscus-aspheric surface for avoiding optical damage induced by ghost images of the fourth order for $1 \omega, 2 \omega$, and $3 \omega$. The BSG and MDS are made with $8 \mathrm{~mm}$-thick fused silica possessing a $0.2 \%$ low-efficiency grating on the input surface for energy sampling. This setup provides transitions from the near-vacuum FOA environment to the hard-vacuum target chamber environment. The disposable debris shield is $2 \mathrm{~mm}$-thick borosilicate glass. Here, the angle of the normal direction of the BSG and MDS to the DDS and the direction of the incident beam is $13.5^{\circ}$, which is used to deviate ghosts below the fourth order for $1 \omega_{0}, 2 \omega_{0}$ and $3 \omega_{0}$ from the direction of the incident beam. Inside the prototype FOA, the pressure is 10 Torr with 10 SLPM before the laser shot and 50 Torr with 40 SLPM after the laser shot using clean dry nitrogen to purge.

\section{Clean-gas control}

The optics in the prototype FOA are coated with a sol-gel anti-reflection film, but residuary $(0.5 \%-1 \%)$ reflection also exists. Hence, these eight optics (including 16 surfaces) could form thousands of ghost images within the fourthorder reflection. If these ghost images are located on the optics, the optics would be directly damaged; if these ghost images move to other parts such as the mechanism, wire and silica gel (the paste around the optical elements, to guarantee the stability of the stress and deformation), the optics would

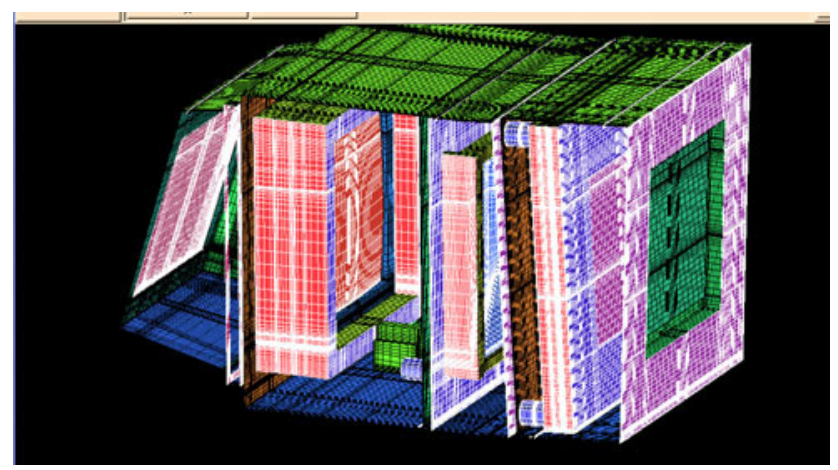

Figure 2. Numerical model of the FOA generated by ICEMCFD.

be indirectly damaged because of the contaminants. As shown in the last section, the BSG, MDS and DDS are tilted by $13.5^{\circ}$, and most of the ghost images are deflected from the main beam path to protect the optics. These ghost images lead to another problem, i.e., the presence of contaminants. To avoid contaminant sputtering to the optics, the following procedures are performed. First, the mechanism surfaces are treated with anodic oxidation. Second, clean gas is used to blow the optics surface to eliminate contaminants. In this section, a numerical simulation is carried out based on the FOA construction and a blowpipe arrangement, and the experimental results are presented.

\subsection{Simulation analysis}

The main physics process involved in the prototype FOA is the convection-diffusion process in the slit cavity (as indicated in Figure 1). The governing equations for this process can be written as

$$
\begin{gathered}
\frac{\partial \rho}{\partial t}+\frac{\partial}{\partial x_{k}}\left(\rho V_{k}\right)=0 \\
\frac{D V_{j}}{D t}=-\frac{1}{\rho_{0}} \frac{\partial\left(P-P_{0}\right)}{\partial x_{j}}+v \frac{\partial^{2} V_{j}}{\partial x_{k} \partial x_{k}}, \\
\frac{D c}{t}=\Gamma \frac{\partial^{2} c}{\partial x_{k} \partial x_{k}},
\end{gathered}
$$

where $V_{i}$ is the velocity vector $(i=1,2,3), t$ is time, $\rho$ is the density of $\mathrm{N}_{2}, v$ is the kinematic viscosity of $\mathrm{N}_{2}, c$ is the density of the aerosol in $\mathrm{N}_{2}, p$ is the pressure of $\mathrm{N}_{2}, p_{0}$ is the reference pressure, and $\rho_{0}$ is the density in the reference point. Equation (1) is the continuity equation, Equation (2) is the momentum equation, and Equation (3) is the composition equation.

The standard $k-e$ model is used in the numerical simulation. This model is based on the hexahedron, and the gridding number is 2.9 million, as shown in Figure 2. The gridding is optimized with the Smoother tools of the Integrated Computer Engineering and Manufacturing code 


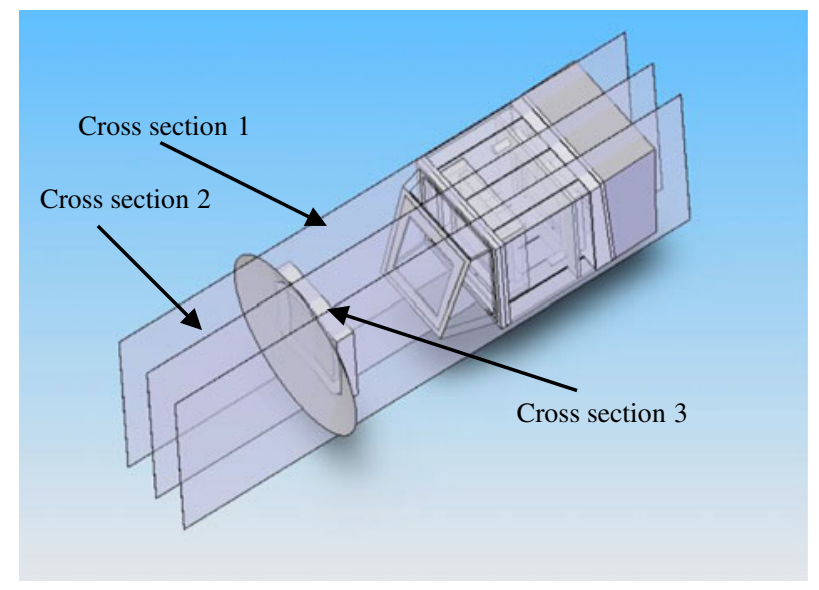

Figure 3. Schematic of the observed cross-section distributions in the prototype FOA.

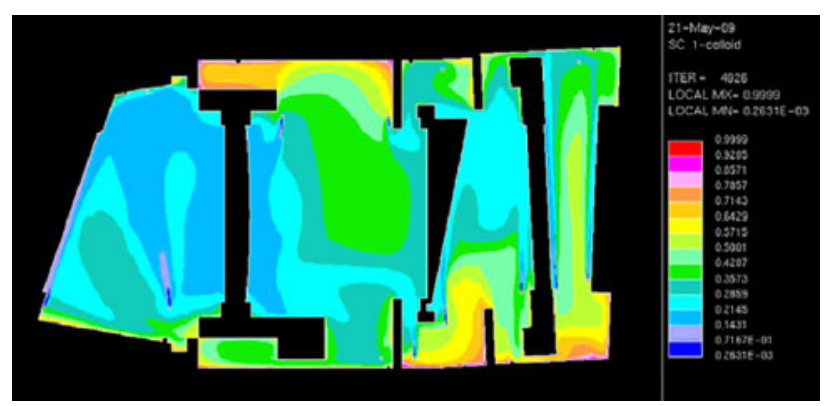

Figure 4. Density distribution of the contaminants in cross-section 2 as the flux ranges within $1-51 \mathrm{~s}^{-1}$ after $30 \mathrm{~s}$.

for Computational Fluid Dynamics (ICEMCFD) based on the condition that the quality of the deformation rate above 0.8 is $>90 \%$ and that all deformation rates are $>0.3$. The deformation rate is defined as the ratio of the diameter of the excircle to that of the incircle. A larger deformation rate corresponds to higher grinding quality.

Based on the above model, three cross-sections are analyzed, as shown in Figure 3. Flow situations of the flow field in the cavities of the prototype FOA at 100 Torr and constant pressure flux of 5 or $501 \mathrm{~s}^{-1}$ are simulated. Then, the ventilation efficiency on the optics surfaces and the density distribution of contaminants in the FOA are investigated for the above two fluxes. An entrance and an exit also exist in each cavity of the FOA.

The simulation results show that both 5 and $50 \mathrm{ls}^{-1}$ fluxes can maintain the relative density of the contaminants on the optics surfaces below $20 \%$ when the designed inlet pipe, exhaust pipe and spatial distribution are used. About $50 \mathrm{~s}$ after the laser launch, the contaminants decrease to $0.1 \%$ when $51 \mathrm{~s}^{-1}$ is used and $6 \%$ when $501 \mathrm{~s}^{-1}$ flux is used, as shown in Figure 4. Therefore, considering the contamination-elimination time, the flux is chosen within $1-51 \mathrm{~s}^{-1}$ and a $180 \mathrm{~s}$ period.

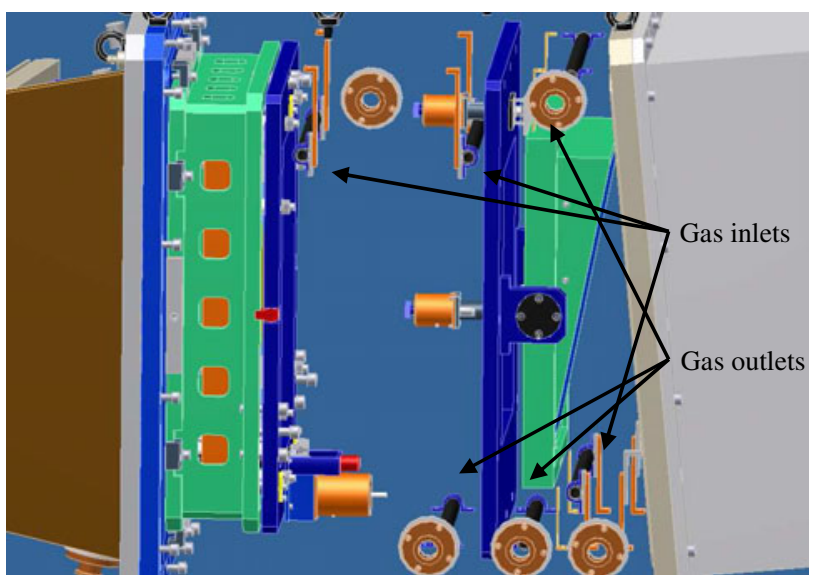

Figure 5. Distribution of the gas inlets and outlets in the FOA.

(a)

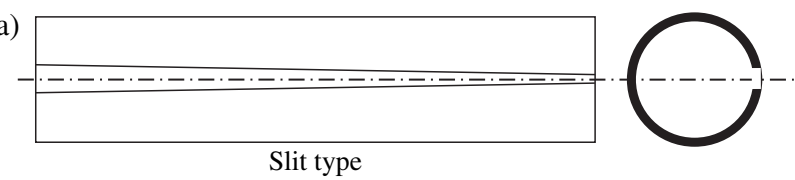

(b)

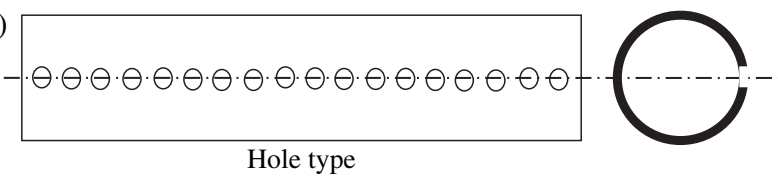

Figure 6. Two types of inlet and exhaust pipes.

\subsection{Gas-blowing scheme}

In this section, the sizes, quantities and positions of the entrance and the exit as well as the gas-flow rate and hold time required for the contaminant elimination are given, based on numerical analysis of the gas-flow characteristics in the prototype FOA. Figure 5 shows the distributions of the inlet pipes and the corresponding flanges. The FOA includes nine entrances and five exits.

The $\mathrm{N}_{2}$ used is $99.99 \%$ pure, and the $\mathrm{H}_{2} \mathrm{O}$ content is less than $3 \mathrm{ppm}$. Gas is transported to the location where the aerosol needs to be blown by the inlet pipe. Figure 6 presents two types of inlet and exhaust pipes. To ensure uniform speed of the gas flow along the axial direction, the slit width is gradually increased from the point near the entrance to that near the exit for the slit-type pipe, as shown in Figure 6(a). For the small hole type (Figure 6(b)), the hole diameter is increased and the distance between the adjacent holes is decreased gradually from the point near the entrance to that near the exit.

The configurations of the exhaust pipes are similar to those of the inlet pipes. To ensure uniform speed of the exhaust flow along the axial direction, the slit width is gradually increased from the point near the exit to the far end for the slit-type pipe. For the small hole type, the hole diameter is increased and the distance between the adjacent holes 


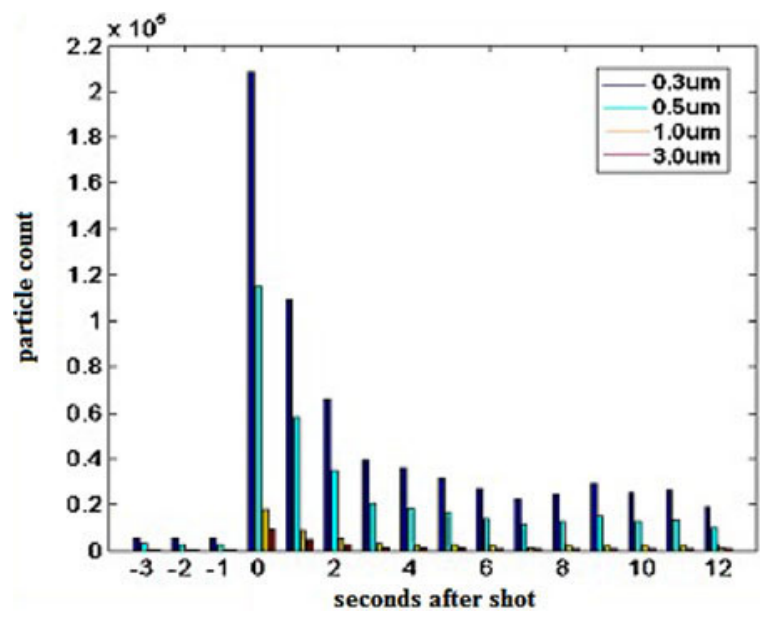

Figure 7. Graph showing the real-time contaminant quantity.

is gradually decreased from the point near the exit to the far end.

\subsection{Experimental results}

In the experiment, the flow controller is triggered at the same time as the laser fires. The flow flux is 40 SLPM. The particle

(a)

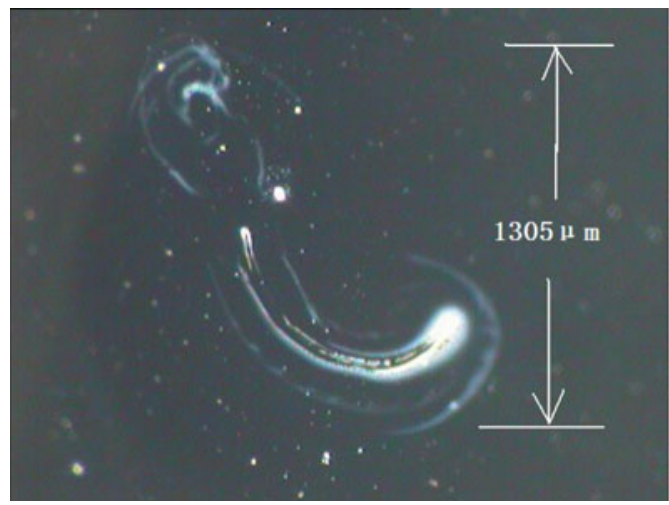

(c)

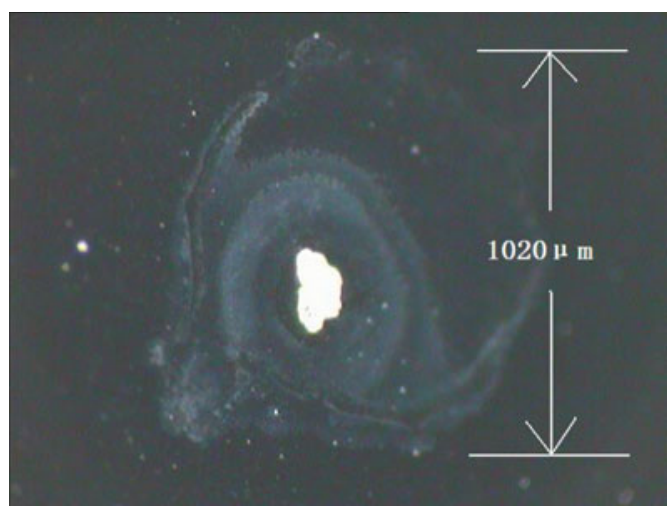

counter is used to detect contamination. Figure 7 shows that the contaminant quantity increases from 3000 particles before the laser fires to 140000-210000 particles after the firing. Thus, the particle density contrast is about 1:70. The optics surfaces is spotted after 33 shots. During the experiment, results obtained by the particle counter are taken from one of the exits. Hence, these results represent the relative density variation of the contaminants rather than the absolute quantity.

\section{Optical damage}

\subsection{Damage morphology induced by the contaminants}

Using an Msu25D high-resolution microscope, damage morphology is detected. Figure 8 shows the presence of surface 'mooning' damage and a surface spot located outside the clear aperture and induced by contaminants apart from the common damage morphologies, such as surface pinpoint damage, block peeling, long scratching, and bulk filament ${ }^{[7-9]}$. Here, surface mooning damage is serious in the center and changes the color of the film, induced by metal contaminants.

The components and morphologies of the contaminants are different; thus, the damage morphologies are also

(b)

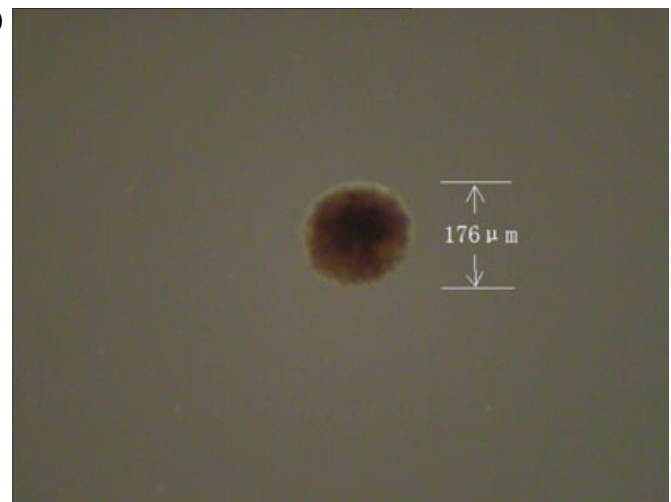

(d)

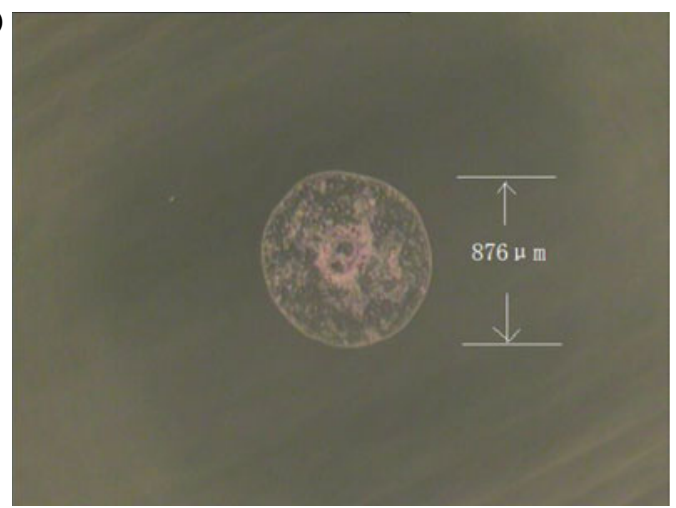

Figure 8. Surface damage morphologies induced by contaminants: (a) film damage located on the clear aperture brim, (b) surface spot outside the clear aperture, (c) clear aperture brim and (d) surface 'mooning' damage outside the clear aperture. 
(a)

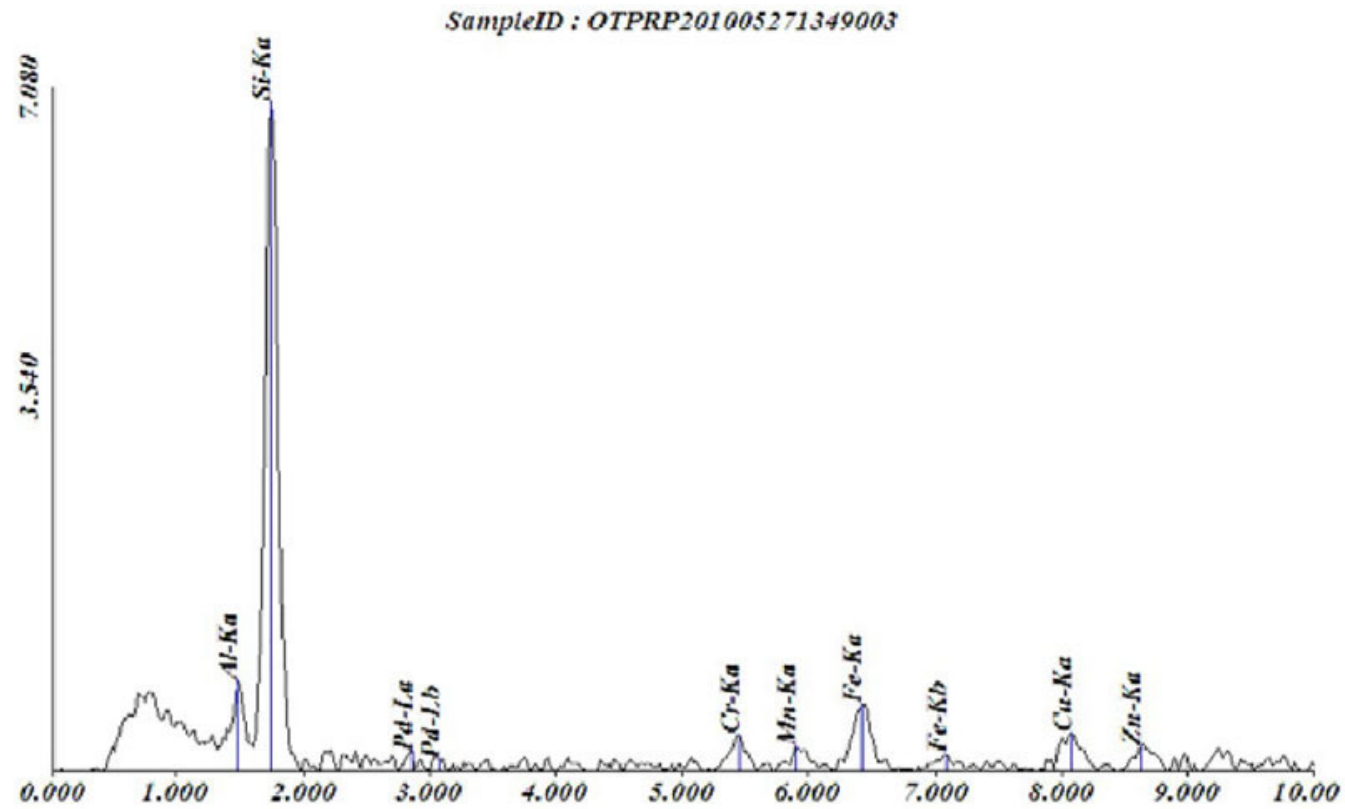

(b)

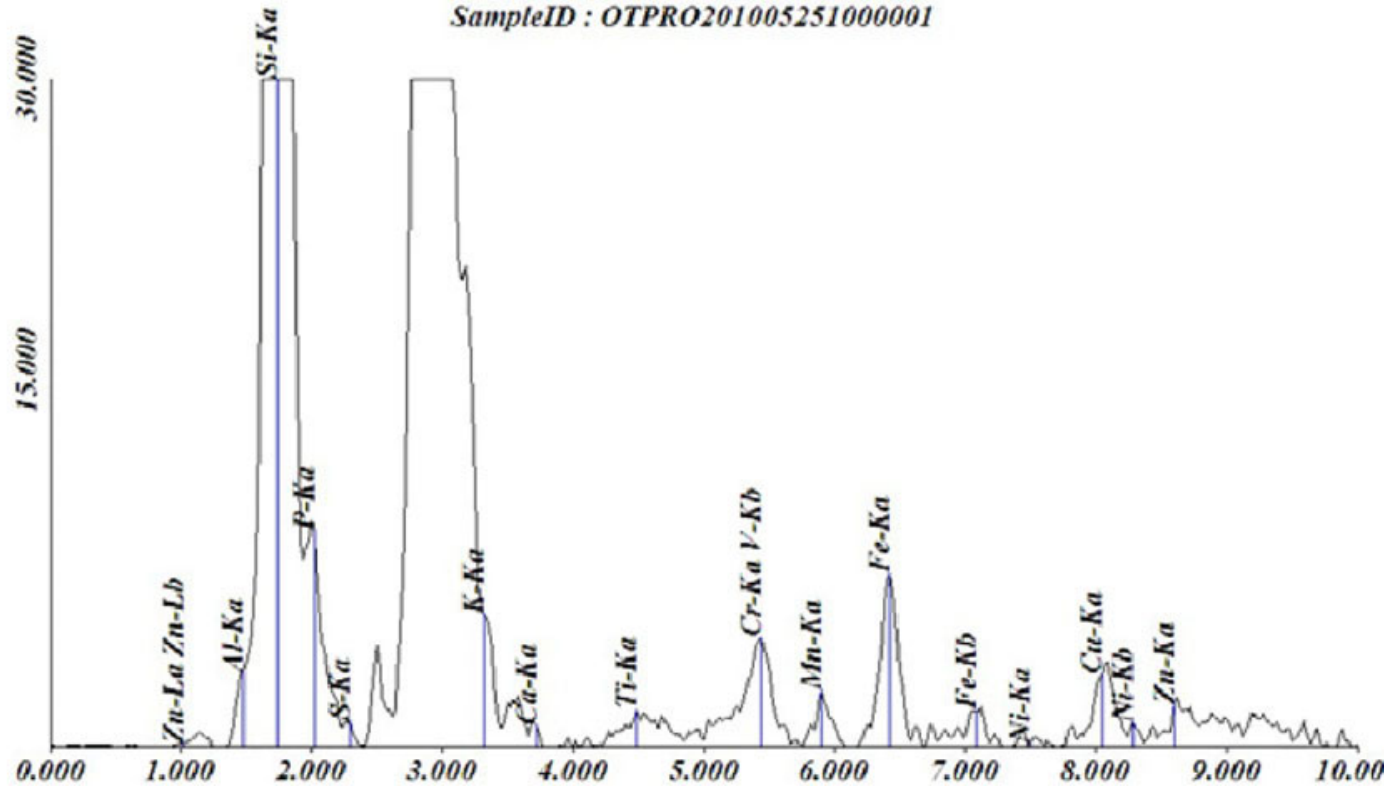

Figure 9. Results obtained by x-ray fluorescence spectrometry: (a) unused silica coated by sol-gel film (including $\mathrm{Al}, \mathrm{Si}, \mathrm{Pd}, \mathrm{Cr}, \mathrm{Mn}, \mathrm{Fe}, \mathrm{Cu}$ and $\mathrm{Zn}$ ) and (b) used silica coated by sol-gel film (including $\mathrm{Zn}, \mathrm{Al}, \mathrm{Si}, \mathrm{P}, \mathrm{S}, \mathrm{K}, \mathrm{Ca}, \mathrm{Ti}, \mathrm{Cr}, \mathrm{Mn}, \mathrm{Fe}, \mathrm{Ni}$ and $\mathrm{Cu}$; because the $\mathrm{Pb}$ amount is negligible, it is not labeled).

different. The different figure subparts are explained as follows.

(a) Figure 8(a) is induced by millimeter order fibers absorbing on the optics surfaces. After less than $0.1 \mathrm{~J} \mathrm{~cm}^{-2}$ order laser irradiation, the fiber is ablated and induces film damage. Suffering from multiple irradiations, the damage size increases and induces substrate damage. Given that the heat absorption coefficient of the fiber is low, this kind of damage cannot induce catastrophic bulk peeling. (b) Figure 8(b) is induced by wire and silica gel. Occurrences of this kind of morphology are numerous on the optics surfaces. If the wire and silica gel are irradiated by a laser, parts of them volatilize and are then absorbed on the optics surfaces. After several irradiations by stray light, they appear ablated but do not damage the sol-gel film.

(c) Figure 8(c) is induced by millimeter order metal contaminants. The substrate is damaged, and the surface 'mooning' damage of the sol-gel film appears. This 
kind of damage is due to the optics surface being affected by metal particle sputtering. After less than $0.1 \mathrm{~J} \mathrm{~cm}^{-2}$ order laser irradiation, the damage size increases and the sub-millimeter order damage points are uniformly distributed in the clear aperture because of the high absorption coefficient of the metal.

(d) Figure $8(d)$ is induced by the same millimeter order metal contaminants. The substrate is seriously damaged in the center, and surface 'mooning' damage of the sol-gel film appears in the periphery. This phenomenon is also induced by the metal contaminants but occurs outside the clear aperture and is irradiated by the stray light.

\subsection{Component analysis of the contamination}

Parameters such as the components of the laser-induced damage point, the irradiated point without damage and the un-irradiated point, as well as the mechanical material, wire, silica gel, unused silica and chemical films, are analyzed by energy-dispersive X-ray fluorescence spectrometry. Figure 9 shows that the new components $\mathrm{S}, \mathrm{P}, \mathrm{K}, \mathrm{Ca}, \mathrm{Mn}, \mathrm{Al}$ and $\mathrm{Pd}$ appear and that the contents of the $\mathrm{Fe}$ and $\mathrm{Cu}$ increase in the used optics compared with the unused optics. Al and $\mathrm{Pd}$ come from the sol-gel film; S, P and $\mathrm{K}$ are from the silica gel used to fix the optics; $\mathrm{Ti}$ and $\mathrm{Cu}$ come from the metal material sputtering of the prototype FOA. Molecular contaminants were not analyzed by Raman spectrometry because of the large optics size $(360 \mathrm{~mm} \times 370 \mathrm{~mm})$.

\section{Conclusions}

The uniform distribution of hundred-micron-order punctiform damage in the clear aperture and the uniform distri- bution of 'mooning' damage or surface spots outside the clear aperture suggest that the contaminants induced by stray light because of the residual reflection from the mechanical metals, silica gel and wire are the main reasons for the damage increase. The gas flow used in the experiment eliminates certain contaminants, but ineffectively. Surface treatment of the metallic material is not completely effective for elimination of contaminants. Stray light absorbing traps are required in the prototype.

\section{References}

1. S. H. Glenzer, B. J. MacGowan, P. Michel, N. B. Meezan, L. J. Suter, S. N. Dixit, J. L. Kline, G. A. Kyrala, D. K. Bradley, D. A. Callahan, E. L. Dewald, L. Divol, E. Dzenitis, M. J. Edwards, A. V. Hamza, C. A. Haynam, D. E. Hinkel, D. H. Kalantar, J. D. Kilkenny, O. L. Landen, J. D. Lindl, S. LePape, J. D. Moody, A. Nikroo, T. Parham, M. B. Schneider, R. P. J. Town, P. Wegner, K. Widmann, P. Whitman, B. K. F. Young, B. Van Wonterghem, L. J. Atherton, and E. I. Moses, Science 327, 1228 (2010).

2. B. M. Van Wonterghem, S. C. Burkhart, C. A. Haynam, K. R. Manes, C. D. Marshall, J. E. Murray, M. L. Spaeth, D. R. Speck, S. B. Sutton, and P. J. Wegner, Proc. SPIE 5341, 55 (2004).

3. Z. Lin, Chin. J. Lasers 37, 2202 (2010).

4. D. Zhao, G. Zhen, P. Shao, N. Hua, Z. Qiao, Y. Dai, and J. Zhu, Chin. J. Lasers 34, 637 (2007).

5. C. A. Haynam, P. J. Wegner, J. M. Auerbach, M. W. Bowers, S. N. Dixit, G. V. Erbert, G. M. Heestand, M. A. Henesian, M. R. Hermann, K. S. Jancaitis, K. R. Manes, C. D. Marshall, N. C. Mehta, J. Menapace, E. Moses, J. R. Murray, M. C. Nostrand, C. D. Orth, R. Patterson, R. A. Sacks, M. J. Shaw, S. B. Sutton, W. H. Williams, C. C. Widmayer, R. K. White, S. T. Yang, and B. M. Van Wonterghem, Appl. Opt. 46, 3276 (2007).

6. Z. Lin, S. Wang, and D. Fan, Chin. J. Lasers B10, IV6 (2001).

7. D. Zhao, L. Wang, Z. Lin, P. Shao, L. Ji, Z. Cai, R. Wu, Y. Dai, and J. Zhu, Chin. J. Lasers 38, 0702001 (2011).

8. S. Papemov and A. W. Schmid, Proc. SPIE 7132, 71321J (2008).

9. T. I. Suratwala, P. E. Miller, J. D. Bude, R. A. Steele, N. Shen, M. V. Monticelli, M. D. Feit, T. A. Laurence, M. A. Norton, C. W. Carr, and L. L. Wong, J. Am. Ceram. Soc. 94, 416 (2011). 